\title{
Community participation during Covid-19
}

\section{Sathiadas MG}

Coronavirus disease COVID-19 is an infectious disease caused by severe acute respiratory syndrome coronavirus 2 (SARS-CoV-2), first identified in December 2019 in Wuhan, China, and has since spread globally, resulting in an ongoing pandemic. Sri Lanka is also affected in a considerable manner. Lifting the lockdown and curfew will increase the chance of community spread. Hence preventive measures practiced by the community in large will reduce the spread of infection. The WHO recommends staying at home, avoiding crowded places, keeping distance from others, washing hands with soap and water often and for at least 20 seconds, practicing good respiratory hygiene, and avoiding touching the eyes, nose, or mouth with unwashed hand. (1)

Public awareness and community participation are crucial in the current situation. Even with the initial widespread publicity regarding pandemic, majority of the people in the community seem to be unaware of the critical nature of the pandemic and harbor misconceptions about protection against a pandemic SARS-CoV-2 strain. (2) It is aggravated by the fact that majority of the people are socioeconomically disadvantaged and have a low-income dependent on a daily wage. This leads to potential loss of income or job and thereby being non-compliant to the government recommendations, such as home isolation. (3) We can overcome the noncompliance by increasing community participation.

Community participation is emphasized by the Global health community where the public and healthcare officials work as a team in health promotion, research and delivery of services. Community engagement has proven to be effective in controlling HIV AIDS and Ebola pandemics especially in tracking and dealing with rumours. $(3,4)$ It cannot be established overnight, a meaningful relationship between communities, health care providers and the government have to be nurtured to ensure it's sustainability especially in the low-income and marginalized group where access to information may be a problem.
Investing funds on long term goals is far more important than in the short term emergency care. Creating spaces for public to participate especially in decision making along with the policy makers will help the decisions to be implemented at the community levels with ease. Clarity and transparency of decision-making, along with thorough and efficient communication of information to the public, are essential part to engage the community in controlling the pandemic.

In the northern part of the country the societies have community groups and these groups can be part of the pandemic response team along with the health services and politicians in building future resilience. These pandemic response teams at community levels will have the local knowledge of the problems the people face especially in the underprivileged areas, thereby it will be plausible to provide and educate them regarding the pandemic. By working together, the public will believe that their wellbeing is valued and their needs are addressed, which in turn will help increase compliance with restrictions and maintain the discipline that is needed to reduce the spread.

Volunteering in the emergency is one other aspect the community can help in the pandemic. Helping in the hospitals, distributing food and medicine to elderly and sick people who cannot leave their homes are some areas where volunteering can be encouraged. (5) Community engagement also helps relieve burdens on health and safety agencies by enabling more members of the public to assume the role of responder rather than being the victim.

Main drawback of the community engagement is the collective good of voluntarism is presently weak and creates private acts of stockpiling and disaster ready households. Community participation cannot be forced into a population but must be self-realized and given the opportunity to participate.

\section{"There is no power for change than a community that discovering what it cares about"}

Margaret $J$ Wheatley 


\section{References:}

1. Corona virus disease advice for the public. WHO publication. https://www.who.int/emergencies/ diseases/novel-coronavirus-2019/advice-forpublic. Accessed on 30-05-2020

2. Helen Marshall, Philip Ryan, Don Roberton, Jackie Street, and Maureen Watson, 2009: Pandemic Influenza and Community Preparedness. American Journal of Public Health 99, S365_S371, https://doi. org/10.2105/AJPH.2008.153056

3. Nguyen V-K, Ako CY, Niamba P, Sylla A, Tiendrebeogo I. Adherence as therapeutic citizenship: impact of the history of access to antiretroviral drugs on adherence to treatment. AIDS. 2007; 21: S31-S35
4. Gillespie AM, Obregon R, El Asawi R et al. Social mobilization and community engagement central to the Ebola response in west Africa: lessons for future public health emergencies. Glob Health Sci Pract. 2016; 4: 626-646

5. Villadiego L Spaniards find beauty in helping each other amid COVID-19 crisis. A1 Jazeera. March 23, 2020; https://www.aljazeera. $\mathrm{com} /$ indepth/features/spaniards-find-beautyhelping- covid-19-crisis-200319105933362. html

6. Marston, C., Renedo, A., \& Miles, S. (2020). Community participation is crucial in a pandemic. Lancet (London, England), S0140-6736(20)31054-0. Advance online publication. https://doi.org/10.1016/S01406736(20)31054-0 